\title{
Experimental and Numerical Study Determining the Warpage Phenomenon of Thin-Wall Injection Molding
}

\author{
Yueh-Tzu Huang, ${ }^{1}$ Chiung-Fang Huang, ${ }^{1,2}$ Bou-Yue Peng, ${ }^{3,4}$ Chun-Wei Chang, ${ }^{5}$ \\ Hsing-Chung Cheng, ${ }^{1,3}$ Yi Lin, ${ }^{6}$ Yung-Kang Shen $\mathbb{D}^{2,7}$ and Hao Wang ${ }^{8}$ \\ ${ }^{1}$ Division of Family and Operative Dentistry, Department of Dentistry, Taipei Medical University Hospital, Taipei, Taiwan, China \\ ${ }^{2}$ School of Dental Technology, College of Oral Medicine, Taipei Medical University, Taipei, Taiwan, China \\ ${ }^{3}$ School of Dentistry, College of Oral Medicine, Taipei Medical University, Taipei, Taiwan, China \\ ${ }^{4}$ Division of Oral and Maxillofacial Surgery, Department of Dentistry, Taipei Medical University, Taipei, Taiwan \\ ${ }^{5}$ Division of Prosthodontics, Department of Dentistry, Taipei Medical University Hospital, Taipei, Taiwan \\ ${ }^{6}$ Department of Business Administration, Takming University of Science and Technology, Taipei, Taiwan, China \\ ${ }^{7}$ Research Center for Biomedical Devices, Taipei Medical University, Taipei, Taiwan, China \\ ${ }^{8}$ Department of Mechanical Engineering, Faculty of Engineering, National University of Singapore, 9 Engineering Drive 1, Singapore \\ 117575
}

Correspondence should be addressed to Yung-Kang Shen; ykshen@tmu.edu.tw

Received 29 May 2020; Revised 18 September 2020; Accepted 7 October 2020; Published 28 October 2020

Academic Editor: Gyorgy Szekely

Copyright (c) 2020 Yueh-Tzu Huang et al. This is an open access article distributed under the Creative Commons Attribution License, which permits unrestricted use, distribution, and reproduction in any medium, provided the original work is properly cited.

\begin{abstract}
This study emphasizes the warpage phenomenon of thin-walled parts using acrylonitrile-butadiene styrene (ABS) plus polycarbonate (PC) plastics for optimal processing by thin-wall injection molding. The authors first employed the Moldflow software to analyze the runner's balance on multicavities for thin-walled parts and to simulate the warpage of thin-walled parts with thin-wall injection molding. Then, this study used those data to fabricate a real mold by computer numerical control machining. For this study, the authors fabricated thin-walled parts and measured their warpage using various process parameters (injection speed, injection pressure, mold temperature, packing time, and melt temperature) with thin-walled injection molding. Finally, the authors found that the most important processing parameter was the packing time for warpage phenomenon of thin-walled parts by thin-wall injection molding.
\end{abstract}

\section{Introduction}

Thin-wall injection molding is used to manufacture thinwalled structures and is among the most common and versatile methods to mass-produce complex plastic parts. If a part's thickness is $3 \mathrm{~mm}$, then it is called a plate. A part $0.2 \sim 0.3 \mathrm{~mm}$ thick is called a thin plate, and a part with a thickness of $<200 \mu \mathrm{m}$ is called a thin film. Thin-wall injection molding is utilized for parts with a thickness of $<1 \mathrm{~mm}$ or when the ratio of flow length to thickness of the part exceeds 100 [1]. Shen [2] used microinjection molding and microinjection compression molding to manufacture microstructures of light-guiding plates. The mold temperature was the main process parameter in both processes. Although thinwall injection molding is not an easy method, the interplay among beta process conditions, mold geometry, and material properties is extremely complex. Ozcelik and Sonat [3] studied warpage and structures of thin-shell cell phone covers produced with polycarbonate (PC)/acrylonitrile-butadiene styrene (ABS) by injection molding. The most influential parameter affecting the warpage property of the thin-shell plastic was the packing pressure. When the authors conducted a structural analysis, the strongest materials were $15 \%$ carbon fiber reinforced PC/ABS, 15\% carbon fiber reinforced ABS, PC, PC/ABS, and ABS. Yang et al. [4] discussed the manufacturing process for microinjection molding with 
various ultra-thin parts (of 100,250 , and $500 \mu \mathrm{m}$ in thickness). The flow resistance of the plastic melt increased as the cavity became thinner. The thinner the cavity was, the smaller the operating window was. Oktem et al. [5] determined that the Taguchi optimization method could reduce a part's warpage depending on process parameters for thinwall plastic components during injection molding. The packing pressure had the greatest impact on warpage with thin-wall injection molding.

Kurtaran and Erzurumlu [6] studied efficient minimization of warpage of thin-shell parts (a bus ceiling lamp base) by integrating a finite element analysis, statistical design of the experiment method, response surface methodology, and a genetic algorithm. Liao et al. [7] determined the optimal process conditions for thin-wall injection molding applied to cellular phone covers. The packing pressure was the most important process parameter affecting the shrinkage and warpage of those thin-walled parts. Sanchez et al. [8] presented deflection values obtained from injected parts measured without contact and by varying only the cooling parameters (temperature, cooling time, and coolant flow rate conditions). Cooling time was a more significant parameter for reducing warpage, while the melt temperature was less important, and the coolant flow rate had an almost negligible effect. Azaman et al. [9] simulated injection molding of shallow, thin-walled parts composed of lignocellulosic polymer composites ( $\mathrm{PP}+50 \%$ wood). The volumetric shrinkage and warpage of the thin-walled parts were evaluated under various process conditions (mold temperature, cooling time, packing pressure, and packing time). The cooling time and packing time were found to have less of an effect on shrinkage and warpage.

There are so many researches to investigate the warpage analysis in injection molding by numerical simulation and soft computing. Nguyen et al. [10] applied the Moldex 3D to simulate the warpage of lightweight hybrid products, and the packing pressure was found to be the most significant parameter influencing warpage. Taghizadeh et al. [11] predicted the warpage of a circular injection molded using artificial neural network based on various processing parameters. The holding pressure and melt temperature have the most, and mold temperature has the least effect on the part warpage. Zhao and Cheng [12] presented a hybrid multiobjective optimization system (adaptive Kriging surrogate modeling) for minimizing the warpage and cycle time of the plastic injection molding process. Two combinations of factors are statistically significant on warpage: melt temperature and packing time and packing pressure and packing time. Hidayah et al. [13] used response surface methodology combined the AMI software as the optimization approach in order to obtain the initial setting of process parameters in injection molding that may lead to the minimization of warpage. From ANOVA result, melt temperature is the most significant factor that give influenced to the formation of warpage.

Sudsawat and Sriseubasi [14] used the optimization approach to generate suitable process setting of multiresponses of the minimization of warpage and volume shrinkage by response surface methodology with genetic algorithm and firefly algorithm techniques in plastic injection molding. The four factors of processing parameter are significant, namely, melt temperature, packing time, packing pressure, and cooling time, as showing the main effect of warpage and volume shrinkage. Masato et al. [15] analyzed the impact of the injection molding processing conditions on the dimensional accuracy of thin-wall fiber reinforced parts. The experimental results appeared that melt temperature and packing pressure were the processing parameters that most affected the shrinkage and warpage of thin-wall parts. Sreedharan and Jeevanantham [16] tried to find the effect of processing parameters on the shrinkage rate of an ABS component in automotive components during the injection molding process. The final observation using $\mathrm{S} / \mathrm{N}$ ratio is derived that the melt temperature plays a major role in shrinkage reduction on the molded part. Singh et al. [17] emphasized the multiresponse optimization of injection molding process parameters by multiple response consideration using cycle time and warpage. The results revealed the melt temperature of $235^{\circ} \mathrm{C}$, injection pressure of $60 \mathrm{MPa}$, packing pressure of $30 \mathrm{MPa}$, and packing time of 5 seconds have the minimum value on warpage of injection molded part. Sudsawat and Sriseubasi [18] achieved the minimization of warpage of an injection molded part by design of experiment (DOE), response surface methodology (RSM), firefly algorithm (FA), and annealing treatment. The results showed that packing time, cooling time, and melt temperature are the most significant factors influencing warpage reduction. In annealing treatment process, warpage phenomenon reduced more from optimization stage at $76.32 \%$ by using annealing process at $85^{\circ} \mathrm{C}$ and 120 minutes. Zhang et al. [19] aimed at the warpage of a thin-walled plastic part, the Moldflow and ANSYS software combined with the orthogonal experimental method were used for multiparameter coupling analysis to calculate the warpage of plastic part. The important influence factors for the plastic part's warpage were packing pressure, packing time, cooling plan, mold temperature, and melt temperature. Among them, packing pressure was the most significant factor.

The optimal processing of products was important on various industry and biocompanies. Székely et al. [20] applied a central composite face design of experiments (DoE) for the optimization and robustness testing of an LC-MS/MS method for the trace analysis of potentially genotoxic 1,3-diisopropylurea. An optimization central composite face (CCF) DoE was conducted leading to the early discovery of carry-over effect which was further investigated in order to establish the maximum injectable sample load. Murray et al. [21] discussed the potential benefits of the "Design of Experiments" approach to reaction optimization for the development of new methodology. A particularly important factor in the development of new chemical reactions is the choice of solvent which can often drastically alter the efficiency and selectivity of a process. Didaskalou et al. [22] demonstrated an efficient and, given the high yield and enantiomeric excess, eminently suitable membrane-based synthesis-separation platform for asymmetric organocatalysis. A catalytic membrane cascade reactor was developed for an integrated synthesis-purification process allowing at 

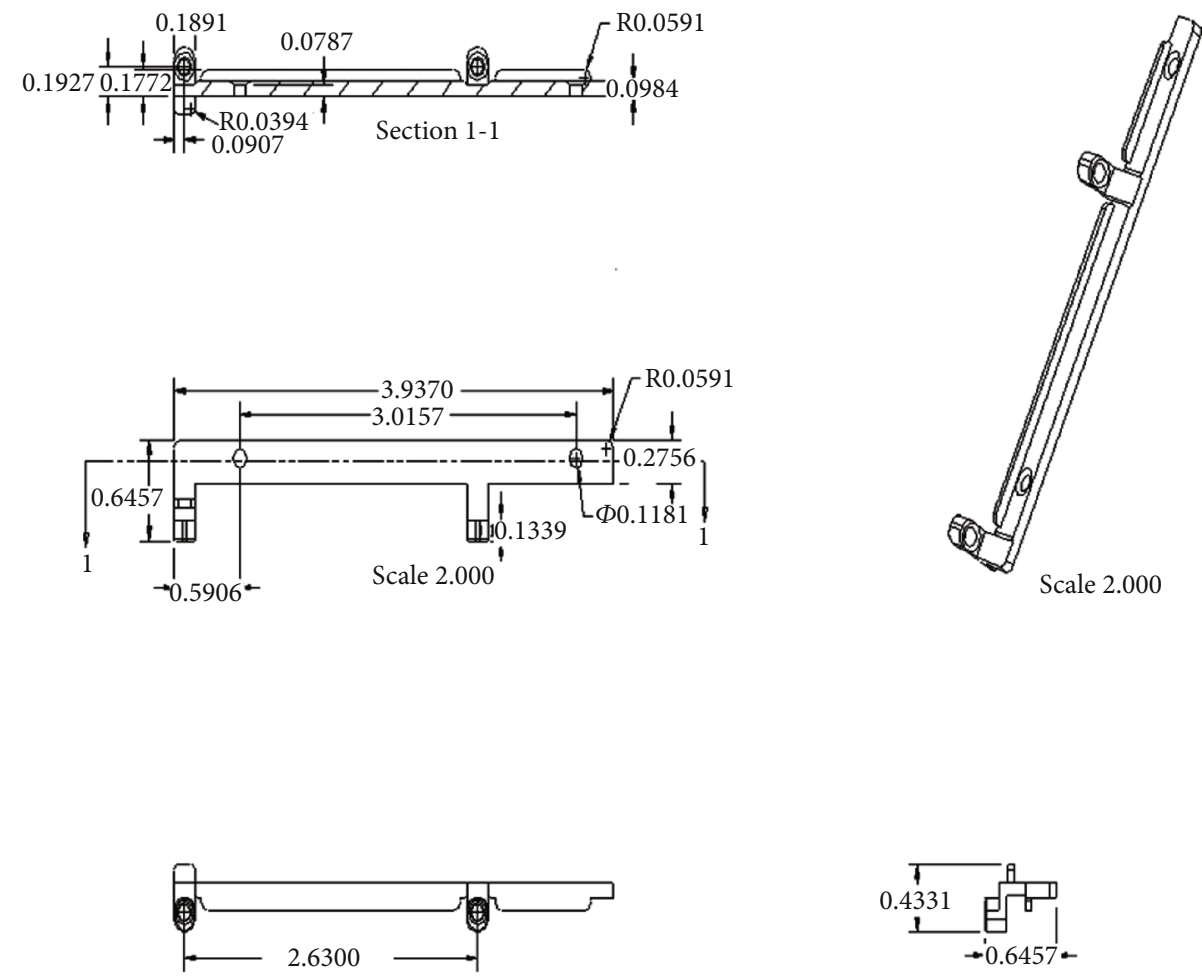

Figure 1: Dimensions of the thin-walled part (units: $\mathrm{cm}$ ).

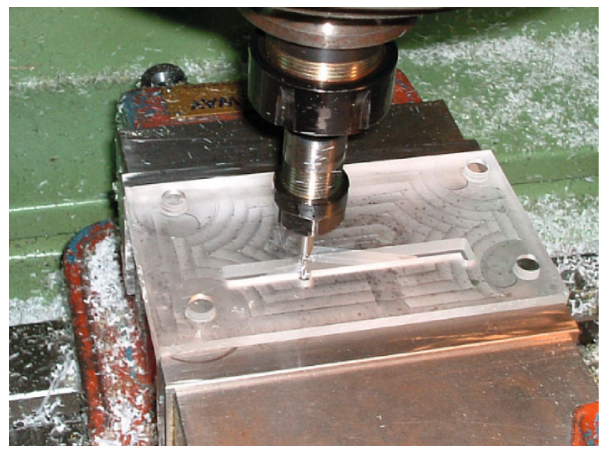

(a) Mold cavity fabrication by $\mathrm{CNC}$

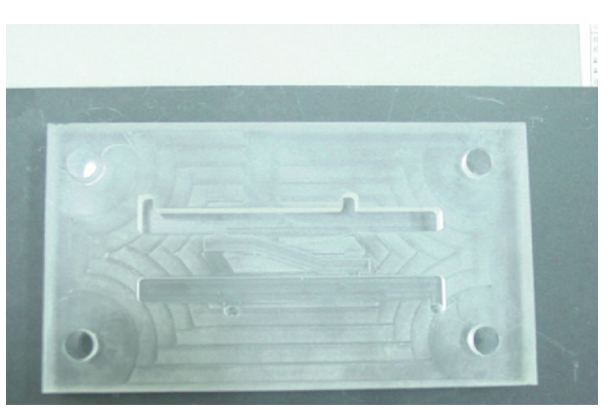

(c) Cavity for the stationary part

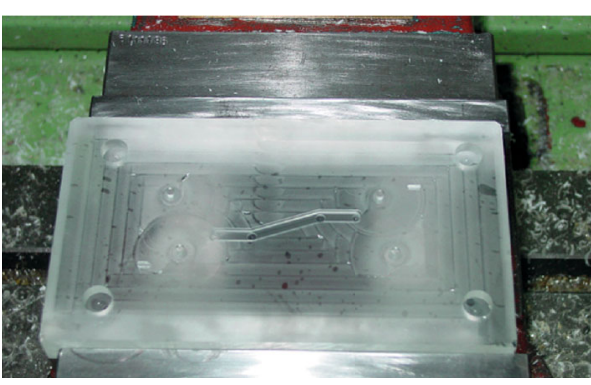

(b) Master cavity for the moving part

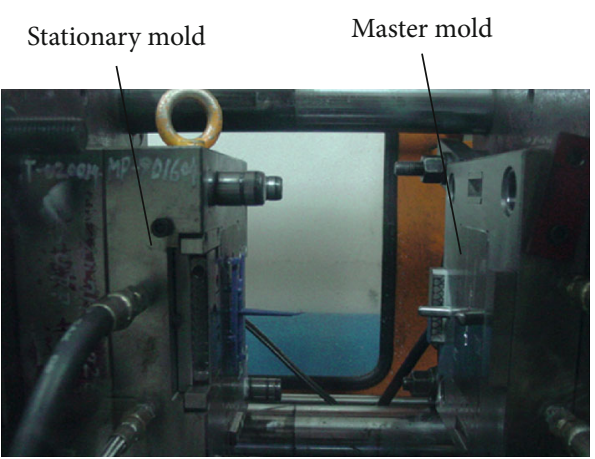

(d) Mold located on the injection molding machine

FIGURE 2: Fabrication of the mold cavity and the mold assembled on the injection molding machine.

least $98 \%$ product and substrate recovery and quantitative in situ solvent recycling. Cao et al. [23] combined the DoE approach for materials optimization with machine-learning analysis to enable the experimentalist to use scarce resources more effectively, time being one of the scarcest, and to have a higher probability of arriving at a true optimum. The 
ultimate key to progressing from the DoE approach of laboratory experimentation to machine learning is the generation of large data sets, which is particularly challenging in the case of devices.

In this study, the authors fabricated thin-walled parts using ABS+PC material by thin-wall injection molding. The process parameters of thin-wall injection molding evaluated included the injection speed, injection pressure, mold temperature, packing time, and melt temperature. This study simultaneously compared the warpage phenomenon of thin-walled parts with experimental and numerical simulations. Warpage measurements were conducted with a noncontact coordinate measurement machine (CMM). The aim of this study was to emphasize the minimum warpage of thin-walled parts by the Taguchi method with thin-wall injection molding. Finally, the optimal processing method of thin-walled parts with thin-wall injection molding applied to mass producing was determined.

\section{Materials and Methods}

2.1. Experimental. Figure 1 reveals the dimensions of the thin-walled part (the support structure of a computer hard disk). This study applied thin-wall injection molding to fabricate this thin-walled part.

A two-plate mold was utilized during thin-wall injection molding. The mold cavities were fabricated by a computer numerical control (CNC) process. The molded material used NAK-80, and its hardness was $350 \mathrm{HMV}$. The inlet gate of this two-plate mold employed a sidewall pin gate. Figure 2 shows fabrication of the mold cavity and its assembly on the injection molding machine. An injection molding machine (220S, ARBURG, Germany) was used for all experiments and had a screw diameter of $18 \mathrm{~mm}$ and a clamping force of 25 tons. The mold temperature control machine was a 300 S (REGLOPLAS, Switzerland). It had a precision of $\pm 1^{\circ} \mathrm{C}$. This study used ABS+PC (C $\left.1200 \mathrm{HF}, \mathrm{GE}, \mathrm{USA}\right)$ materials to manufacture the thin-walled part via thin-wall injection molding. In this study, the authors wanted to find the warpage phenomenon of thin-walled parts with optimal processing of thin-wall injection molding. The processes for thin-wall injection molding that the authors evaluated were the injection speed (A), injection pressure (B), mold temperature $(\mathrm{C})$, packing time (D), and melt temperature (E). Table 1 shows the values of the process parameters for the $\mathrm{ABS}+\mathrm{PC}$ materials using thin-wall injection molding. The ranges of injection speed, injection pressure, and packing time accumulated from the laboratory experience and the combination of the performance of the injection molding machine. The destruction temperature of $\mathrm{ABS}+\mathrm{PC}$ is $250^{\circ} \mathrm{C}$; the authors defined that the melt temperature must be smaller than $250^{\circ} \mathrm{C}$. So the authors let the ranges of melt temperature between $215^{\circ} \mathrm{C}$ and $230^{\circ} \mathrm{C}$. The mold temperature is generally adjusted at $45-90^{\circ} \mathrm{C}$ for $\mathrm{ABS}+\mathrm{PC}$ on the authors' lab. The authors applied the ranges of mold temperature between $60^{\circ} \mathrm{C}$ and $90^{\circ} \mathrm{C}$. To sum up, the ranges of processing parameters of thin-wall injection molding reference partly from the ideas of the authors, partly from the performance of the machine, and partly from the authors' experience. To
TABLE 1: Process parameters for thin-wall injection molding using ABS+PC materials.

\begin{tabular}{lcccc}
\hline Level/parameter & Level 1 & Level 2 & Level 3 & Level 4 \\
\hline A. Injection speed $(\mathrm{mm} / \mathrm{s})$ & 97 & 98 & 99 & 100 \\
B. Injection pressure $(\mathrm{MPa})$ & 55 & 60 & 65 & 70 \\
C. Mold temp. $\left({ }^{\circ} \mathrm{C}\right)$ & 60 & 70 & 80 & 90 \\
D. Packing time $(\mathrm{s})$ & 3 & 4 & 5 & 6 \\
E. Melt temp. $\left({ }^{\circ} \mathrm{C}\right)$ & 215 & 220 & 225 & 230 \\
\hline
\end{tabular}

TABLE 2: The $L_{16}$ orthogonal array used in the main experiment (Exp.).

\begin{tabular}{lccccc}
\hline Exp. & $\begin{array}{c}\text { Injection } \\
\text { speed (A) }\end{array}$ & $\begin{array}{c}\text { Injection } \\
\text { pressure } \\
(\mathrm{B})\end{array}$ & $\begin{array}{c}\text { Mold } \\
\text { temperature } \\
(\mathrm{C})\end{array}$ & $\begin{array}{c}\text { Packing } \\
\text { time (D) }\end{array}$ & $\begin{array}{c}\text { Melt } \\
\text { temperature } \\
(\mathrm{E})\end{array}$ \\
\hline 1 & 1 & 1 & 1 & 1 & 1 \\
2 & 1 & 2 & 2 & 2 & 2 \\
3 & 1 & 3 & 3 & 3 & 3 \\
4 & 1 & 4 & 4 & 4 & 4 \\
5 & 2 & 1 & 2 & 3 & 4 \\
6 & 2 & 2 & 1 & 4 & 3 \\
7 & 2 & 3 & 4 & 1 & 2 \\
8 & 2 & 4 & 3 & 2 & 1 \\
9 & 3 & 1 & 3 & 4 & 2 \\
10 & 3 & 2 & 4 & 3 & 1 \\
11 & 3 & 3 & 1 & 2 & 4 \\
12 & 3 & 4 & 2 & 1 & 3 \\
13 & 4 & 1 & 4 & 2 & 3 \\
14 & 4 & 2 & 3 & 1 & 4 \\
15 & 4 & 3 & 2 & 4 & 1 \\
16 & 4 & 4 & 1 & 3 & 2 \\
\hline
\end{tabular}

identify the relative significance of these four process parameters, various experiments were performed during $4^{5}$ runs. A statistics-based experimental design method, the Taguchi method [24], was utilized to reduce the numbers of experimental runs (Table 2).

When a thin-walled part is fabricated, its allowance error is very important. Analysis of warpage phenomenon of thinwalled parts was the primary task of this study. The authors used optimal processing to determine relationships between process parameters and warpage of thin-walled parts by thin-wall injection molding. A CMM was employed to measure product dimensional errors of the thin-walled parts. A three-dimensional (3D) laser scanner (LSH-II-150, Hawk, Nextc, England) was used to determine the warpage of the thin-walled parts. When the authors measure the thinwalled part, the two block gauges (specification: $18 \times 60 \times$ 150) are used as the reference for fixing the thin-walled part on the measurement platform ( $T$ axis) and then fix the thin-walled part to the block gauge with double-sided tape. Because the laser scanner instrument has better accuracy for light-colored measurement objects, but the surface of the block gauge is a smooth mirror surface, in order to 


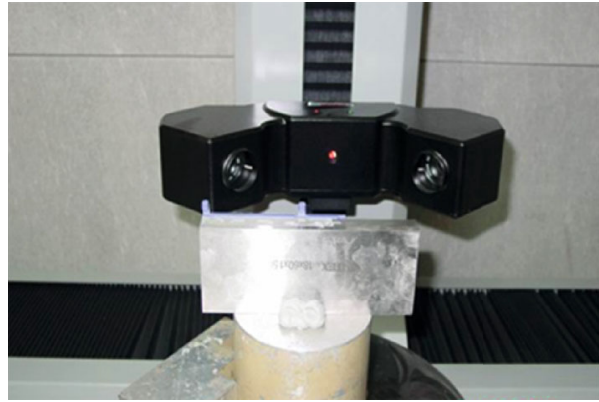

(a) The thin-walled part and laser scanning instrument

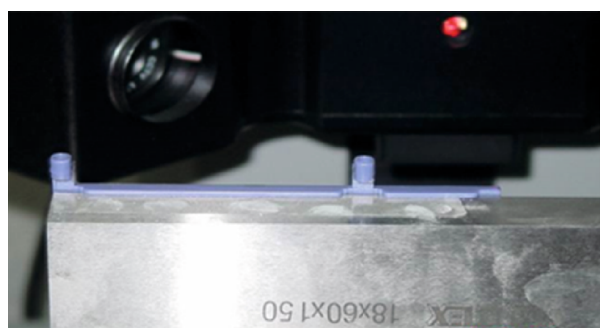

(b) The measurement for thin-walled part

FIGURE 3: The warpage measurement on a thin-walled part.

measure the accuracy of the result, a thin layer is sprayed on the surface of the block gauge powder paint (Figure 3). The tolerance of the laser scanner was $<0.05 \mathrm{~mm}$ for measurements of $<0.5 \mathrm{~m}$, which was sufficient to measure the warpage phenomenon because the deformation of thin-walled parts was more than ten times higher than this value. The laser scanner used to measure the thin-walled part was divided into 12 points with a $9 \mathrm{~mm}$ pitch as a scan measurement interval along the longitudinal direction of the thinwalled part. The measurement time consumed only tens of seconds for each thin-walled part. The finished thin-walled product was randomly sampled from among the experimentally produced products, and five samples were taken as a measurement sample. After the warpage value of each thinwalled part was measured, the average value was taken.

2.2. Numerical Simulation. This study used the Moldflow software to simulate the warpage phenomenon of thinwalled parts by thin-wall injection molding. The governing equations for mass, momentum, and energy conservation for a nonisothermal, generalized Newtonian fluid are as follows:

Continuity equation:

$$
\frac{D \rho}{D t}=\frac{\partial \rho}{\partial t}+\nabla \cdot(\rho \vec{u})=0,
$$

Momentum equation:

$$
\rho \frac{D \vec{u}}{D t}=-\nabla p+\eta \nabla^{2} \vec{u}+\rho \vec{g}
$$

Energy equation:

$$
\rho c_{p} \frac{D T}{D t}=k\left(\nabla^{2} T\right)+\eta \dot{\gamma}^{2} .
$$

Then,

$$
\dot{\gamma}=\nabla \vec{u} \cdot \nabla \vec{u}
$$

where $t$ is the time, $\rho$ is the density, $\vec{u}$ is the velocity vector, $P$ is the pressure, $\vec{g}$ is the gravity vector, $\eta$ is the viscosity, $c_{p}$ is

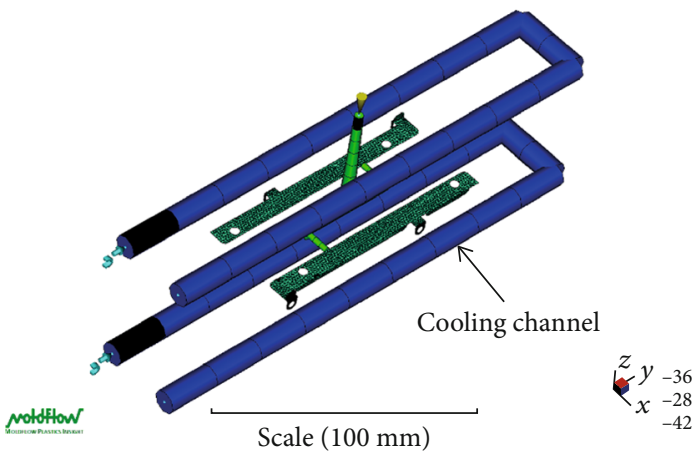

FIgURE 4: A meshing model for numerical simulation (Moldflow).

the specific heat, $k$ is the thermal conductivity, $T$ is the temperature, and $\dot{\gamma}$ is the shear rate.

The viscosity model of a fluid is given by:

$$
\begin{aligned}
\eta(\dot{\gamma}, T, P) & =\frac{\eta_{0}(T, P)}{1+\left(\eta_{0} \dot{\gamma} / \tau^{*}\right)^{1-m}}, \\
\eta_{0}(T, P) & =D_{1} \exp \left[-\frac{A_{1}(T-T *)}{A_{2}+(T-T *)}\right], T>T *, \\
T *(P) & =D_{2}+D_{3} P, \\
A_{2} & =\tilde{A}_{2}+D_{3} P, \text { and }, \\
\eta_{0}(T, P) & =\infty, T>T * ;
\end{aligned}
$$

where $T *$ donates the glass-transition temperature of the polymer and $m$ represents the flow index.

Boundary and initial conditions were as follows:

$\vec{u}=0 ; \quad T=T_{w} ; \frac{\partial P}{\partial n}=0$ at $z= \pm h($ on the mold wall),

$$
\begin{aligned}
\frac{\partial \vec{u}}{\partial z} & =\frac{\partial T}{\partial z}=0 \text { at } z=0 \text { (on the centerline) } \\
P & =0 \text { (on the flow front }), \text { and } \\
\vec{u} & =u(x, y, z, t)(\text { on the inlet })
\end{aligned}
$$




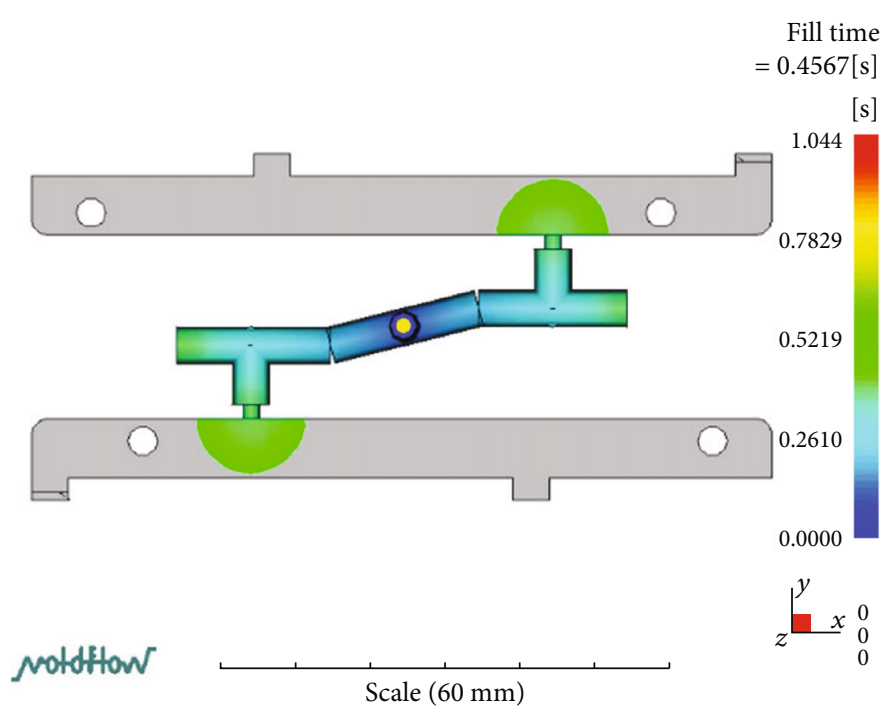

(a) Filling stage: $10 \%$

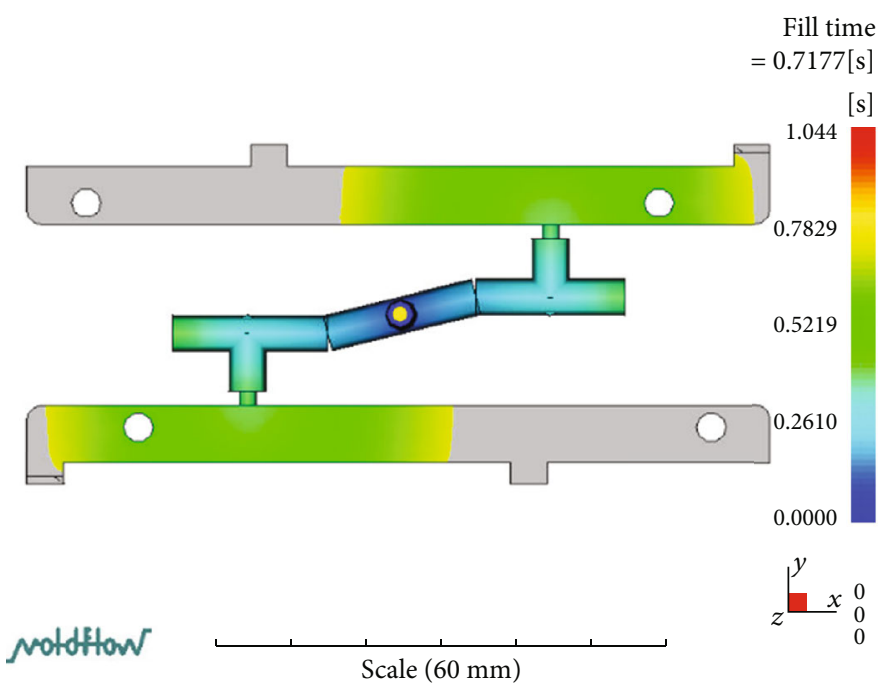

(b) Filling stage: $50 \%$

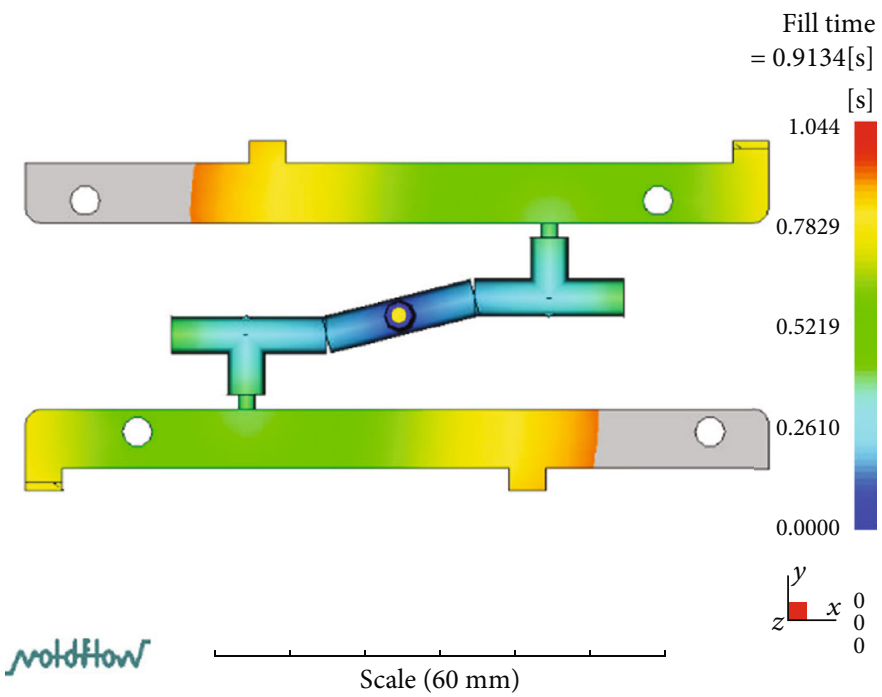

(c) Filling stage: $80 \%$

FIGURE 5: Continued. 


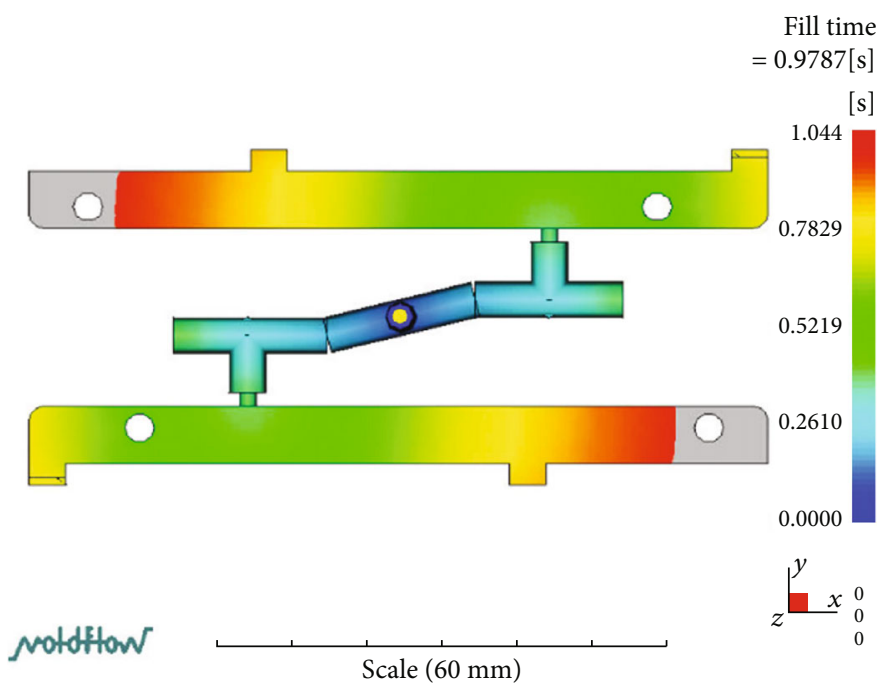

(d) Filling stage: $90 \%$

FIgURE 5: Numerical simulation of the short shot with thin-wall injection molding.

where $T_{w}$ is the mold temperature, $n$ denotes the normal direction, and $u$ represents the inlet velocity.

The energy balance on the solid-liquid interface is represented by:

$$
\begin{gathered}
T_{s}=T_{l}=T_{m} \text { at } z=s(x, y, t) \quad \text { for } \quad t>0 \text { and, } \\
\left.k_{s}\left(\frac{\partial T_{s}}{\partial n}\right)\right|_{z=s(x, y, t)}-\left.k_{l}\left(\frac{\partial T_{l}}{\partial n}\right)\right|_{z=s(x, y, t)}=\rho_{l} L_{h} \frac{\partial s}{\partial t},
\end{gathered}
$$

where $T_{s}$ is the solid temperature, $T_{1}$ is the liquid temperature, $T_{m}$ is the freezing temperature, $s$ is the $z$-coordinate for the solid-liquid interface, $L_{h}$ is the latent heat, $k_{s}$ is the solid thermal conductivity, and $k_{l}$ is the liquid thermal conductivity.

The model contains (a) five independent variables, viz., three velocities $(u, v$, and $w)$, one pressure $(P)$, and one temperature $(T)$ and (b) one dependent variable, viscosity $(\eta)$.

In this study, the governing equations were solved using the control volume finite element method. For details of the numerical simulations, see Shen et al. [25]. The 3D mesh in the Moldflow (5.0 version) analysis was utilized to examine the support structure of the computer hard disk. The mesh is a four-node tetrahedral element. The simulation model had 10,500 meshes and 9512 nodes on the thin-walled part. The calculation time was about $357 \mathrm{~s}$ in each case (Figure 4). A personal computer that contained a Pentium 4 2.8-Gbyte CPU, 1-Gbyte of memory, and a 120-Gbyte hard disk was used.

\section{Results and Discussion}

Figure 5 reveals the short-shot filling stage of the thin-walled part using $\mathrm{ABS}+\mathrm{PC}$ materials in thin-wall injection molding for the numerical simulation. The plastic melt front of each cavity reached similar positions at the filling stages with
TABLE 3: Numerical simulation of the warpage of the thin-walled part.

\begin{tabular}{lc}
\hline Runs & Warpage $(\mathrm{mm})$ \\
\hline$L_{1}$ & 0.399 \\
$L_{2}$ & 0.461 \\
$L_{3}$ & 0.618 \\
$L_{4}$ & 0.812 \\
$L_{5}$ & 0.611 \\
$L_{6}$ & 0.695 \\
$L_{7}$ & 0.408 \\
$L_{8}$ & 0.455 \\
$L_{9}$ & 0.484 \\
$L_{10}$ & 0.405 \\
$L_{11}$ & 0.375 \\
$L_{12}$ & 0.388 \\
$L_{13}$ & 0.381 \\
$L_{14}$ & 0.382 \\
$L_{15}$ & 0.451 \\
$L_{16}$ & 0.401 \\
\hline
\end{tabular}

thin-wall injection molding. Table 3 indicates the warpage of the thin-walled part in the numerical simulation for the $L_{1} \sim L_{16}$ experiments. The $L_{4}$ run had the maximum value of warpage, and the minimum value of warpage occurred on the $L_{11}$ run. The numerical simulation of the warpage analysis for $L_{11}$ is revealed in Figure 6. The minimum warpage value was found at the ends of the thin-walled part, at $0.375 \mathrm{~mm}$. To minimize the warpage of the thin-walled part for various process parameters with thin-walled injection 


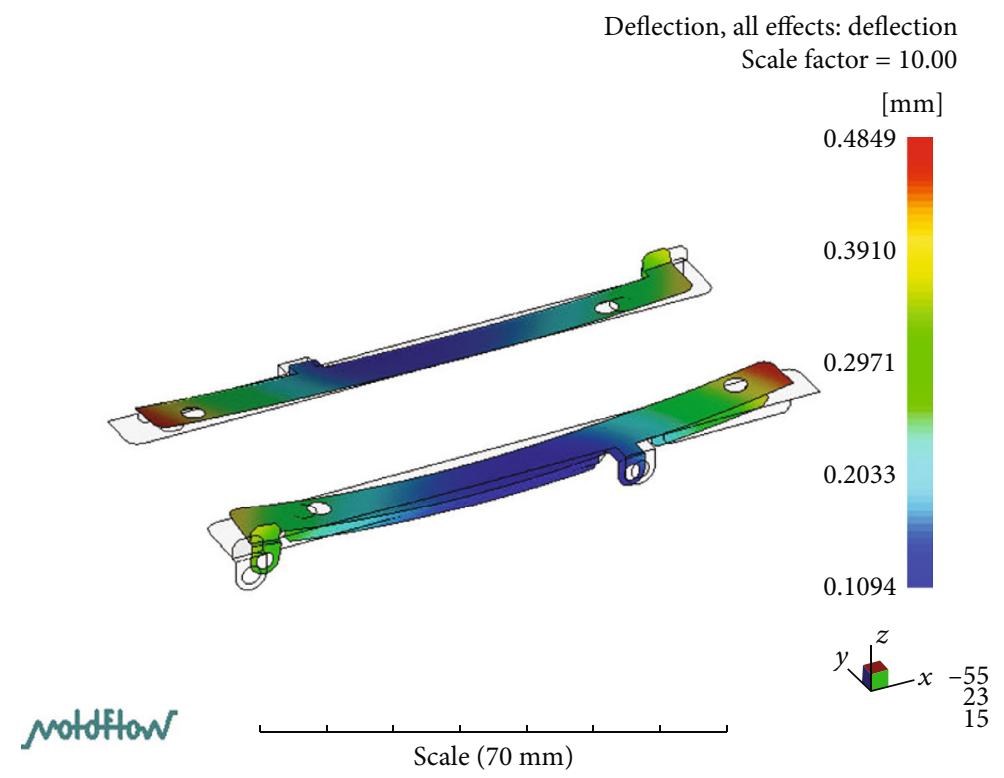

FIgURE 6: Numerical simulation of the distribution of warpage of the thin-walled part for the $L_{11}$ run.

TABLE 4: Numerical simulation of the signal-to-noise $(\mathrm{S} / \mathrm{N})$ ratio reaction of warpage of the thin-walled part.

\begin{tabular}{lccccc}
\hline Parameter level & A & B & C & D & E \\
\hline 1 & 0.399 & 0.381 & 0.375 & 0.382 & 0.399 \\
2 & 0.408 & 0.382 & 0.388 & 0.375 & 0.401 \\
3 & 0.375 & 0.375 & 0.382 & 0.401 & 0.381 \\
4 & 0.381 & 0.388 & 0.381 & 0.451 & 0.375 \\
Effect & 0.033 & 0.013 & 0.013 & 0.076 & 0.026 \\
Rank & 2 & 4 & 4 & 1 & 3 \\
\hline
\end{tabular}

molding regardless in both the experiment and the numerical simulations, the following equation was used for the analysis to describe the smaller-the-better characteristics:

$$
\frac{S}{N}=-10 \log \left\{\frac{1}{n} \sum_{i=1}^{n} \frac{1}{y_{i}^{2}}\right\},
$$

where $y_{i}$ is the measured or numerical simulation property (warpage) and $n$ corresponds to the number of samples in each test trial. This study carried out a numerical simulation of the signal-to-noise $(\mathrm{S} / \mathrm{N})$ ratio reactions of warpage (Table 4) and created an $\mathrm{S} / \mathrm{N}$ reaction diagram of warpage (Figure 7) of the thin-walled part with thin-wall injection molding. The level of the optimal factor that statistically resulted in the minimum warpage of the thin-walled part by numerical simulation was predicted to be A3B3C1D1E4. These optimized factor levels represented an injection speed of $99 \mathrm{~mm} / \mathrm{s}$, an injection pressure of $65 \mathrm{MPa}$, a mold temperature of $60^{\circ} \mathrm{C}$, a packing time of $3 \mathrm{~s}$, and a melt temperature of $230^{\circ} \mathrm{C}$. The numerical simulation results also revealed that the packing time was the most important process parameter, followed in order by the injection speed, melt temperature, mold temperature, and injection pressure on warpage of the thin-walled part with thin-wall injection molding.
After the thin-walled part is fabricated by thin-wall injection molding, this study uses 3D CMM to measure the warpage of thin-walled part in thin-wall injection molding. A laser scanner is a laser beam that undergoes a uniform rotation so that the angle of incidence of the laser beam changes relatively continuously. In addition, the reflection angle is also continuously changed, and the scanning point continuously displayed on the straight line is formed by the action of the parallel light mirror. When an object blocks the scanning spot on the scanning line, if the scanning speed can be mastered, the length of the object can be obtained by the following formula.

$$
L=V \times \Delta t
$$

as $L$ is the test object size, $V$ is the line velocity of scan, and $\triangle t$ is the time of the beam that is blocked.

The laser measurement scanner converts the measurement results into computer-readable coordinate points, which are then displayed on the software interface and can be corrected for measurement errors. The reflection of the laser light high-speed scanning projection is on the computer software interface. The displayed screen is shown below. The laser scanning projection is displayed on the computer software; it seems to be a straight line, but each line is composed of several measurement points during the laser light measurement. However, the distance between each measuring point and the point is $0.15 \mathrm{~mm}$, which can be changed due to the required accuracy of the measured object (Figure 8).

The measured values of warpage of the thin-walled part are listed in Table 5. Values of $L_{1} \sim L_{16}$ are coordinates in the $Z$-direction. The warpage of the thin-walled part means the difference in the maximum value minus the minimum value at 12 coordinate points of measurement for each experiment with thin-wall injection molding. Results also showed that the $L_{11}$ run experiment had the minimum warpage value, which indicated that $L_{11}$ was the best fabrication process. The warpage process conditions of the $L_{11}$ run included 


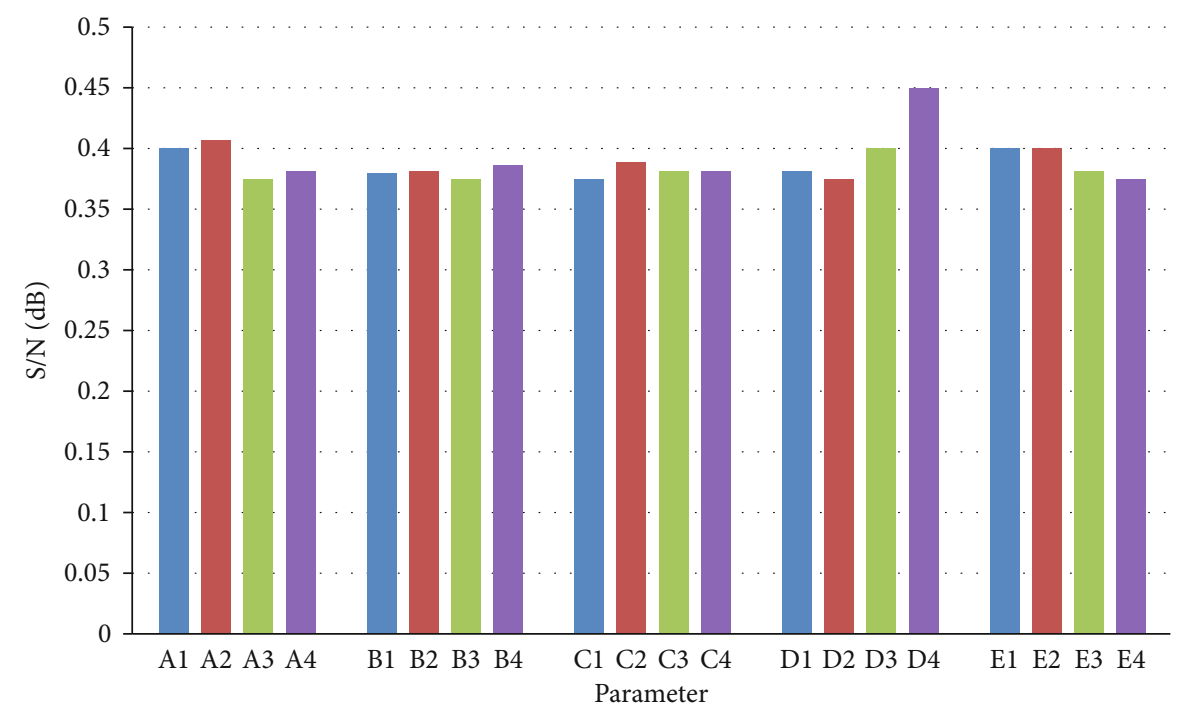

FigURE 7: Variation of the $\mathrm{S} / \mathrm{N}$ ratio with factor level for warpage phenomenon of thin-walled part by numerical simulation.

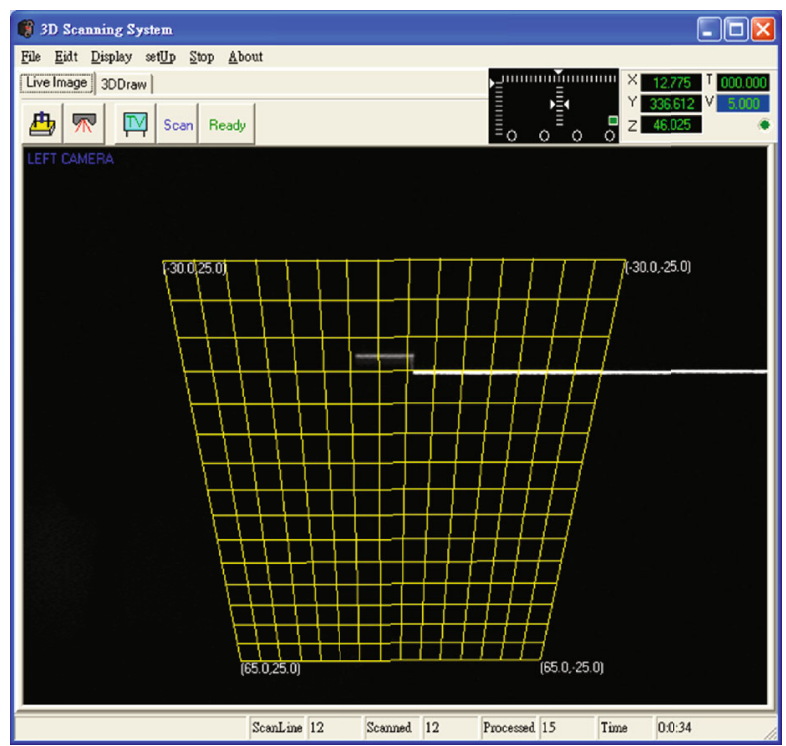

(a) The display of computer values after scanning

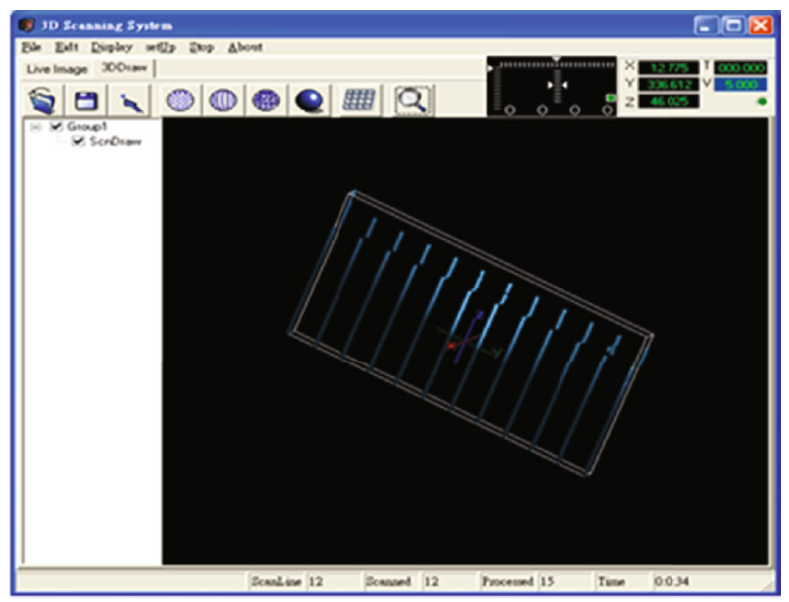

(b) The image of thin-walled part after scanning

FIGURE 8: Convert optical measurement to computer numerical method. 
TABLE 5: Warpage of the thin-walled part in the experiment (using thin-wall injection molding).

\begin{tabular}{|c|c|c|c|c|c|c|c|}
\hline $\begin{array}{l}\text { Coordinate point } \\
\text { Pitch }(\mathrm{mm})\end{array}$ & $\begin{array}{l}1 \\
9\end{array}$ & $\begin{array}{c}2 \\
27\end{array}$ & $\begin{array}{c}3 \\
45\end{array}$ & $\begin{array}{c}4 \\
63\end{array}$ & $\begin{array}{c}5 \\
81\end{array}$ & $\begin{array}{c}6 \\
108\end{array}$ & Difference (mm) \\
\hline$L_{1}$ & 26.603 & 26.379 & 26.268 & 26.21 & 26.342 & 26.593 & 0.393 \\
\hline$L_{2}$ & 26.716 & 26.527 & 26.404 & 26.338 & 26.512 & 26.815 & 0.477 \\
\hline$L_{3}$ & 26.972 & 26.609 & 26.415 & 26.323 & 26.427 & 26.712 & 0.649 \\
\hline$L_{4}$ & 26.966 & 26.588 & 26.394 & 26.212 & 26.318 & 26.503 & 0.754 \\
\hline$L_{5}$ & 26.886 & 26.542 & 26.397 & 26.286 & 26.383 & 26.523 & 0.6 \\
\hline$L_{6}$ & 26.595 & 26.402 & 26.376 & 26.244 & 26.595 & 26.951 & 0.707 \\
\hline$L_{7}$ & 26.634 & 26.387 & 26.229 & 26.223 & 26.358 & 26.623 & 0.411 \\
\hline$L_{8}$ & 26.601 & 26.344 & 26.223 & 26.248 & 26.406 & 26.727 & 0.504 \\
\hline$L_{9}$ & 26.842 & 26.534 & 26.388 & 26.352 & 26.409 & 26.711 & 0.494 \\
\hline$L_{10}$ & 26.713 & 26.393 & 26.313 & 26.302 & 26.379 & 26.545 & 0.411 \\
\hline$L_{11}$ & 26.601 & 26.379 & 26.224 & 26.237 & 26.306 & 26.445 & 0.377 \\
\hline$L_{12}$ & 26.577 & 26.309 & 26.167 & 26.202 & 26.314 & 26.512 & 0.41 \\
\hline$L_{13}$ & 26.702 & 26.43 & 26.34 & 26.312 & 26.372 & 26.586 & 0.39 \\
\hline$L_{14}$ & 26.652 & 26.391 & 26.267 & 26.287 & 26.381 & 26.615 & 0.385 \\
\hline$L_{15}$ & 26.772 & 26.507 & 26.336 & 26.308 & 26.386 & 26.616 & 0.464 \\
\hline$L_{16}$ & 26.559 & 26.328 & 26.309 & 26.396 & 26.543 & 26.739 & 0.429 \\
\hline
\end{tabular}

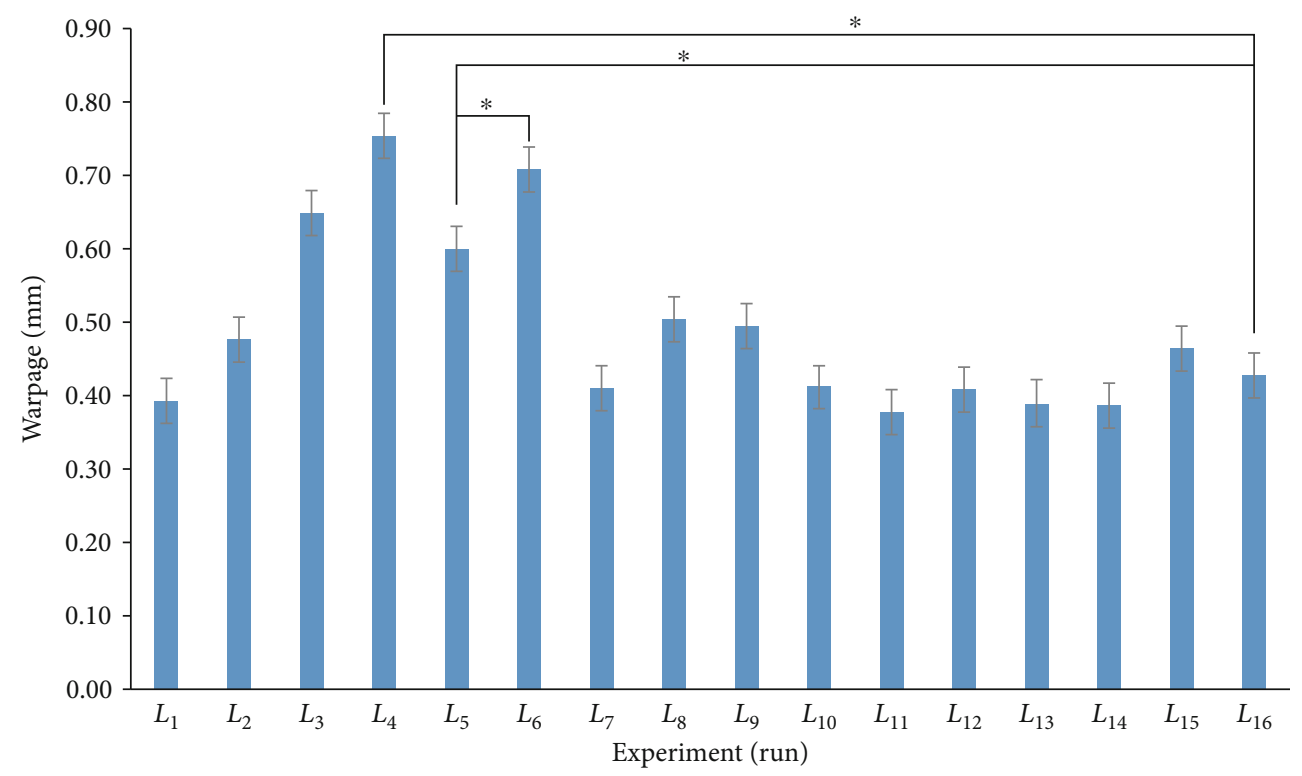

FIGURE 9: Warpage analysis for the $p$ value of various process parameters in experiments $\left({ }^{*} p<0.5\right)$.

TABLE 6: Signal-to-noise $(\mathrm{S} / \mathrm{N})$ ratio reactions of warpage of the thin-wall part for the experiment (with thin-wall injection molding).

\begin{tabular}{lccccc}
\hline Parameter level & A & B & C & D & E \\
\hline 1 & 0.393 & 0.39 & 0.375 & 0.385 & 0.393 \\
2 & 0.411 & 0.385 & 0.41 & 0.375 & 0.411 \\
3 & 0.375 & 0.375 & 0.385 & 0.411 & 0.39 \\
4 & 0.385 & 0.41 & 0.39 & 0.464 & 0.375 \\
Effect & 0.034 & 0.033 & 0.033 & 0.085 & 0.034 \\
Rank & 2 & 3 & 3 & 1 & 2 \\
\hline
\end{tabular}

an injection speed of $99 \mathrm{~mm} / \mathrm{s}$, an injection pressure of $65 \mathrm{MPa}$, a mold temperature of $60^{\circ} \mathrm{C}$, a packing time of $4 \mathrm{~s}$, and a melt temperature of $230^{\circ} \mathrm{C}$. Process conditions of the $L_{4}$ run revealed the maximum value of warpage of the thinwalled part between the experiment and numerical simulation. The process conditions of the $L_{4}$ run included an injection speed of $97 \mathrm{~mm} / \mathrm{s}$, an injection pressure of $70 \mathrm{MPa}$, a mold temperature of $90^{\circ} \mathrm{C}$, a packing time of $6 \mathrm{~s}$, and a melt temperature of $230^{\circ} \mathrm{C}$. This study showed the same results of the warpage analysis of the thin-walled part in both the experimental and numerical simulations. 


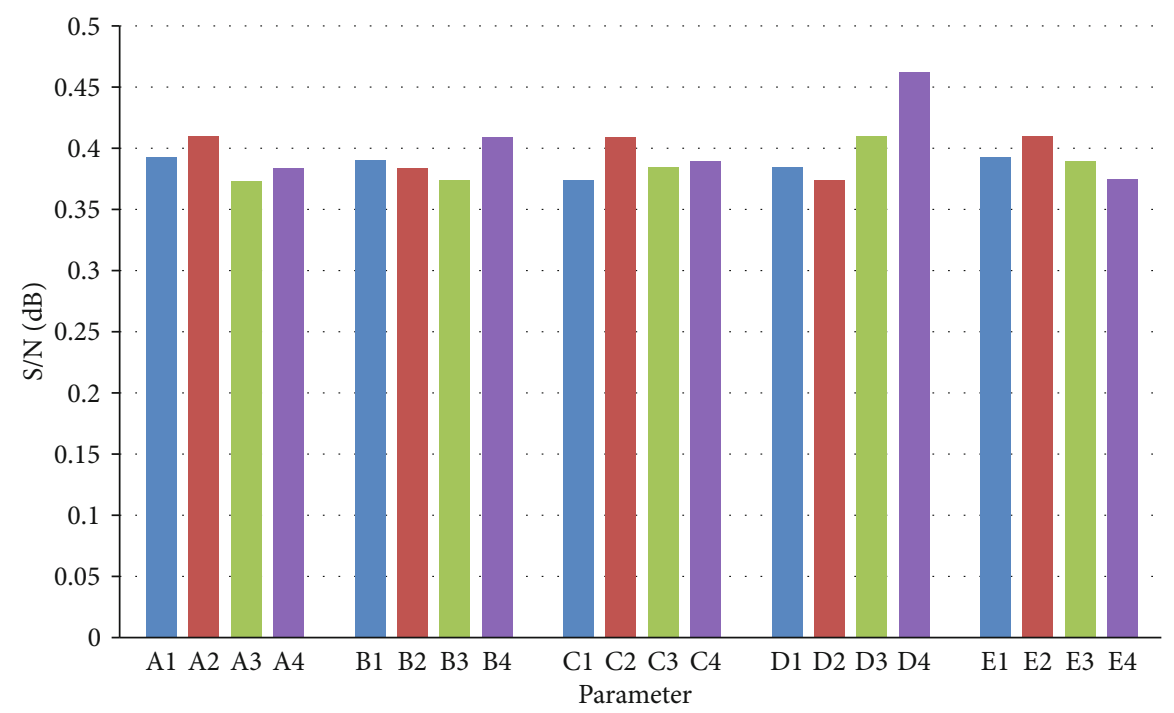

FIGURE 10: Variations in the signal-to-noise (S/N) ratio with factor levels for warpage phenomena of the thin-walled part by the experiments (using thin-wall injection molding).

Figure 9 shows the warpage analysis for the $p$ value of various process parameters in experiments $(* p<0.5)$. The results indicate that the statistically significantly different between $L_{4}$ and $L_{16}, L_{5}$ and $L_{16}$, and $L_{5}$ and $L_{6}$.

Table 6 indicates the $S / \mathrm{N}$ ratio reaction and rank of warpage of the thin-walled part for various process parameters with thin-wall injection molding. Figure 10 indicates $\mathrm{S} / \mathrm{N}$ ratios of the thin-walled part by thin-wall injection molding for various process parameters. Based on these results, the optimal factor levels that statistically resulted in the minimum warpage for thin-wall injection molding were A3B3C1D2E4. These optimized factor levels represent an injection speed of $99 \mathrm{~mm} / \mathrm{s}$, an injection pressure of $65 \mathrm{MPa}$, a mold temperature of $60^{\circ} \mathrm{C}$, a packing time of $4 \mathrm{~s}$, and a melt temperature of $230^{\circ} \mathrm{C}$. The packing time was the most important process parameter for the warpage phenomenon, followed in order by the injection speed and melt temperature, with the mold temperature and injection pressure being unimportant factors. A higher injection speed and higher injection pressure would reduce the filling time of the thin-walled part with thin-wall injection molding. This situation also caused the melt temperature of the plastic to increase and the viscosity of the melted plastic to decrease. Therefore, the flow situation of the melted plastic could easily fill the cavity, and this phenomenon caused less warpage of the thin-walled part. Appropriate differences in the melt temperature and mold temperature facilitated minor differences in the temperature distribution of the plastic in the filling stage of thin-wall injection molding. This situation can lead to smaller warpage of the thin-walled part with thin-wall injection molding. The higher packing time means that more melt plastic goes into the mold cavity and compensates for the shrinkage due to a temperature difference of the product. Therefore, this situation also can reduce the warpage of the thin-walled part. To sum up, the results of warpage of the thin-walled part were very similar between the experiments and numerical simulations with thin-wall injection molding.

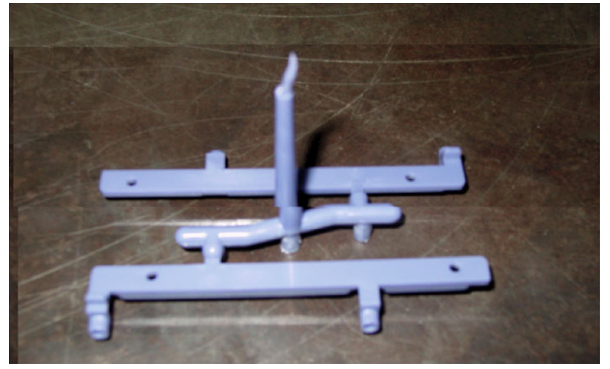

FIGURE 11: The actual thin-walled part by thin-wall injection molding.

Figure 11 shows the molded thin-wall part. Finally, this study could fabricate the thin-walled part very well with thin-wall injection molding, and we can use the resulting data to mass-produce thin-walled parts in the future.

Thin-wall injection molding is utilized for parts with a thickness of $<1 \mathrm{~mm}$ or when the ratio of flow length to thickness of the part exceeds 100 [1]. The ratio of flow length to thickness of the thin-walled part is about 163 in this study. The most important factor of process parameter is the packing time on thin-wall injection molding. In the authors' other research [25], the ratio of flow length to thickness on electronic dictionary battery cover (thin-walled part) is nearly 338. The melt temperature is the most important factor of process parameter during thin-wall injection molding. The ratio of flow length to thickness of an air filter sheet of mobile air conditioner (thin-walled part) is about 238 in the research [19]. The most important factor of process parameter is packing pressure on thin-wall injection molding.

Various ratios of flow length to thickness produce different important factors of process parameter in thin-wall injection molding. Therefore, this study can be included as a reference for the research of thin-wall injection products. In the future, a more complete study should be done for thinwall products with various flow/length ratios at thin-wall injection molding. 


\section{Conclusions}

The goal of this study was to successfully fabricate thinwalled parts by thin-wall injection molding. This study determined optimal process parameters for thin-walled parts using the minimum warpage of the product as the judgment point. The optimal factor levels that statistically resulted in the minimum warpage for thin-wall injection molding were A3B3C1D2E4 regardless of experiments or numerical simulations. Those results indicated that the processing parameter values represented an injection speed of $99 \mathrm{~mm} / \mathrm{second}$, an injection pressure of $65 \mathrm{MPa}$, a mold temperature of $60^{\circ} \mathrm{C}$, a packing time of 4 seconds, and a melt temperature of $230^{\circ} \mathrm{C}$. The packing time was the most important process parameter for the warpage phenomenon, followed in order by the injection speed and melt temperature, with the mold temperature and injection pressure being unimportant factors for the thin-walled part by thin-wall injection molding in both the numerical simulations and experiments. Results of the warpage analysis of the thin-wall injection molded part were very similar for both the numerical simulations and experiment. Ultimately, this study was able to completely fabricate the thin-walled part using thin-wall injection molding. In particular, the design of daily plastic parts related to consumer lunch boxes, medical supplies, and electronic products is getting thinner and thinner. Thin-walled plastic products are widely used in aerospace, dining tables, medical and health, and electronics industries because of their ease of recycling and low environmental pollution. High-speed thinwall injection molding can save materials and time and is one of the important production processes for plastic products in the future.

\section{Data Availability}

No data were used to support this study.

\section{Conflicts of Interest}

The authors declare that they have no conflicts of interest.

\section{Acknowledgments}

The authors would like to thank the NTUT-TMU Joint Research Program for financially supporting this research under contract no. NTUT-TMU-98-13.

\section{References}

[1] N. Kidlik, "Thin wall technique," Injection Molding, vol. 89, 1999.

[2] Y. K. Shen, "Comparison of height replication properties of micro-injection molding and micro-injection compression molding for production of microstructures on lightguiding plate," Plastics, Rubber and Composites, vol. 36, pp. 77-84, 2013.

[3] B. Ozcelik and I. Sonat, "Warpage and structural analysis of thin shell plastic in the plastic injection molding," Materials \& Design, vol. 30, no. 2, pp. 367-375, 2009.
[4] S. Y. Yang, S. C. Nian, S. T. Huang, and Y. J. Weng, "A study on the micro-injection molding of multi-cavity ultra-thin parts," Polymers for Advanced Technologies, vol. 22, no. 6, pp. 891-902, 2011.

[5] H. Oktem, T. Erzurumla, and I. Uzman, "Application of Taguchi optimization technique in determining plastic injection molding process parameters for a thin-shell part," Materials \& Design, vol. 28, no. 4, pp. 1271-1278, 2007.

[6] H. Kurtaran and T. Erzurumlu, "Efficient warpage optimization of thin shell plastic parts using response surface methodology and genetic algorithm," International Journal of Advanced Manufacturing Technology, vol. 27, no. 5-6, pp. 468-472, 2006.

[7] S. J. Liao, D. Y. Chang, H. J. Chen et al., "Optimal process conditions of shrinkage and warpage of thin-wall parts," Polymer Engineering and Science, vol. 44, no. 5, pp. 917-928, 2004.

[8] R. Sanchez, J. Aisa, A. Martinez, and D. Mercado, "On the relationship between cooling setup and warpage in injection molding," Measurement, vol. 45, no. 5, pp. 1051-1056, 2012.

[9] M. D. Azaman, S. M. Sapnan, S. Sulaiman, E. S. Zainudin, and A. Khalina, "Shrinkages and warpage in the processability of wood-filled polypropylene composite thin-walled parts formed by injection molding," Materials and Design, vol. 52, pp. 1018-1026, 2013.

[10] T. K. Nguyen, C. J. Hwang, and B. K. Lee, "Numerical investigation of warpage in insert injection-molded lightweight hybrid products," International Journal of Precision Engineering and Manufacturing, vol. 18, no. 2, pp. 187-195, 2017.

[11] S. Taghizadeh, A. Ozdemir, and O. Uluer, "Warpage prediction in plastic injection molded part using artificial neural network," Iranian Journal of Science and Technology Transaction B-Engineering, vol. 37, pp. 149-160, 2013.

[12] J. Zhao and G. Cheng, "An innovative surrogate-based searching method for reducing warpage and cycle time in injection molding," Advances in Polymer Technology, vol. 35, no. 3, pp. 288-297, 2016.

[13] M. H. N. Hidayah, Z. Shayfull, N. Z. Noriman, M. Fathullah, R. Norshahira, and A. T. N. A. Miza, "Optimization of warpage on plastic part by using response surface methodology (RSM)," AIP Conference, vol. 2030, article 020155, 2018.

[14] S. Sudsawat and W. Sriseubasi, "Optimized plastic injection molding process and minimized the warpage and volume shrinkage by response surface methodology with genetic algorithm and firefly algorithm techniques," Indian Journal of Engineering and Materials Sciences, vol. 24, pp. 228-238, 2017.

[15] D. Masato, J. Rathore, M. Sorgato, S. Carmignato, and G. Lucchetta, "Analysis of the shrinkage of injection-molded fiber-reinforced thin-wall parts," Materials \& Design, vol. 132, pp. 496-504, 2017.

[16] J. Sreedharan and A. K. Jeevanantham, "Analysis of shrinkages in ABS injection molding parts for automobile applications," Materials Today: Proceedings, vol. 5, no. 5, pp. 12744-12749, 2018.

[17] G. Singh, M. K. Pradhan, and A. Verma, "Multi response optimization of injection molding process parameters to reduce cycle time and warpage," Materials Today: Proceedings, vol. 5, pp. 8398-8405, 2018.

[18] S. Sudsawat and W. Sriseubasi, "Warpage reduction through optimized process parameters and annealed process of injection-molded plastic parts," Journal of Mechanical Science and Technology, vol. 32, no. 10, pp. 4787-4799, 2018. 
[19] J. X. Zhang, X. Y. Yin, F. G. Liu, and P. Yang, “The simulation of the warpage rule of the thin-walled part of polypropylene composite based on the coupling effect of mold deformation and injection molding process," Science and Engineering of Composite Materials, vol. 25, no. 3, pp. 593-601, 2018.

[20] G. Székely, B. Henriques, M. Gil, and C. Alvareza, "Experimental design for the optimization and robustness testing of a liquid chromatography tandem mass spectrometry method for the trace analysis of the potentially genotoxic 1,3-diisopropylurea," Drug Testing and Analysis, vol. 6, no. 9, pp. 898-908, 2014.

[21] P. M. Murray, F. Bellany, L. Benhamou, D. K. Bučar, A. B. Tabor, and T. D. Sheppard, "The application of design of experiments (DoE) reaction optimisation and solvent selection in the development of new synthetic chemistry," Organic \& Biomolecular Chemistry, vol. 14, no. 8, pp. 2373-2384, 2016.

[22] C. Didaskalou, J. Kupai, L. Cseri et al., "Membrane-grafted asymmetric organocatalyst for an integrated synthesis-separation platform," ACS Catalysis, vol. 8, no. 8, pp. 7430-7438, 2018.

[23] B. Cao, L. A. Adutwum, A. O. Oliynyk et al., "How to optimize materials and devices via design of experiments and machine learning: demonstration using organic photovoltaics," ACS Nano, vol. 12, no. 8, pp. 7434-7444, 2018.

[24] G. Taguchi, Introduction to Quality Engineering, McGrawHill, New York, NY, USA, 1990.

[25] Y. C. Chiang, H. C. Cheng, C. F. Huang, J. J. Lee, Y. Lin, and Y. K. Shen, "Warpage phenomenon of thin-wall injection molding," The International Journal of Advanced Manufacturing Technology, vol. 55, no. 5-8, pp. 517-526, 2011. 